\title{
On the Specificity of Cyclodextrin Complexes Detected by Electrospray Mass Spectrometry
}

\author{
Valérie Gabelica, ${ }^{*}$ Nives Galic ${ }^{\dagger}$ and Edwin De Pauw \\ Laboratoire de Spectrométrie de Masse, Départment de Chimie, Université de Liège, Liège, Belgium
}

$\alpha$-cyclodextrin complexes with linear $\alpha, \omega$-dicarboxylic acids were investigated by electrospray mass spectrometry. These hydrophobic complexes are known to have an equilibrium binding constant that increases with the diacid chain length. However, the electrospray mass spectrometry (ES-MS) spectra showed that the relative intensity of the complex did not vary significantly with chain length. This contradiction is caused by a contribution of nonspecific adducts to the signal of the complex in ES-MS. In order to estimate the contribution of nonspecific adducts to the total intensity of the complexes with $\alpha$-cyclodextrin, the comparison was made between $\alpha$-cyclodextrin and maltohexaose, the latter being incapable of making inclusion complexes in solution. The signal observed for complexes between diacids and maltohexaose can only result from nonspecific electrostatic aggregation, and is found to be more favorable with the shorter diacids. This is also supported by MS/MS experiments. A procedure is described which allows estimation of the contribution of the nonspecific complex in the spectra of the complexes with $\alpha$-cyclodextrin by using the relative intensity of the complex with maltohexaose. The contribution of the specific complex to the total signal intensity is found to increase with the diacid chain length, which is in agreement with solution behavior. (J Am Soc Mass Spectrom 2002, 13, 946-953) (C) 2002 American Society for Mass Spectrometry

$\mathrm{F}$ or the last ten years, electrospray mass spectrometry (ES-MS) has been used to investigate noncovalent complexes of different classes of compounds [1-6]. Electrospray mass spectrometry can be used basically in two different ways, each giving access to a different kind of information. (1) Full-scan simple MS spectra can be recorded with soft conditions to detect the complexes that are present in the infused solution. (2) Once the complexes of interest are isolated in the gas phase, their intrinsic properties (without any influence of the solvent) can be studied. In the present paper, we will focus on the former aspect, namely whether electrospray mass spectra give a faithful image of the complexes that are present in the solution. ES-MS could eventually become a powerful technique for the analysis of unknown complexes only if all the complexes present in solution, and only them, give a signal in the spectrum. In other words, neither false negatives, nor false positives are permitted.

Different cyclodextrin complexes have already been studied by electrospray mass spectrometry. Cyclodextrins (or CD's, for short) are cyclic oligomers composed of glucopyranose units that are connected through glycosidic $\alpha-1,4$ bonds. The structural consequence of

Published online June 25, 2002

Address reprint requests to Dr. V. Gabelica, Department of Chemistry, Université de Liège, B-4000 Liège, Belgium. E-mail: v.gabelica@ulg.ac.be

*Research fellow of the F.N.R.S.

${ }^{\dagger}$ Present address: Laboratory of Analytical Chemistry, Faculty of Science, University of Zagreb, Strossmayerov Trg 14, HR-10000 Zagreb, Croatia. this binding mode is the formation of a molecule that is shaped like a truncated cone having a narrow rim lined with primary hydroxyl groups, a wide rim lined with secondary hydroxyl groups, and a cavity. The exterior of the cavity is hydrophilic and makes the cyclodextrin water-soluble, while the hydrophobic interior enables cyclodextrins to form inclusion (host-guest) complexes with various molecules. The most probable noncovalent binding mode involves the inclusion of the less polar part of the guest molecule into the cavity, while the more polar group of the guest is exposed to the bulk solvent just outside the wider opening of the cavity [7]. As a general rule, the complex is strong when there is size complementarity between the guest and the cavity of the CD $[8,9]$. $\alpha$-cyclodextrin $(\alpha-\mathrm{CD})$ has six glucopyranose units, $\beta$-cyclodextrin $(\beta-\mathrm{CD})$ has seven glucopyranose units, and $\gamma$-cyclodextrin $(\gamma-\mathrm{CD})$ has eight glucopyranose units $[8,10]$. Molecules containing aliphatic chains fit better into the small cavity of $\alpha-\mathrm{CD}$, while molecules containing phenyl groups fit better into the larger cavity of $\beta$-CD.

Various studies of noncovalent complexes between $\beta$-cyclodextrins and aromatic molecules have shown that the complexes that were known to be present in solution could be detected by ES-MS [11-17]. In all these studies, the aromatic guest molecules were bearing at least one polar group. However, Cunniff and Vouros [18] have reported that ES-MS on complexes with non-aromatic amines gave false positives. Conversely, ES-MS on $\beta$-CD complexes with aromatic non-polar 
Table 1. Relative intensities of $\alpha-C D$ and the complexes with diacids of different chain length for equimolar mixtures $([\alpha-C D]=$ $\left.[1, \mathrm{n}-\mathrm{da}]=4 \times 10^{-4} \mathrm{M}\right)^{\mathrm{a}}$

\begin{tabular}{|c|c|c|c|c|c|}
\hline $\mathrm{n}\left(\mathrm{CH}_{2}\right)$ & $\alpha-\mathrm{CD}(\%)$ & $(1: 1)^{2-}(\%)$ & $(1: 1)^{1-}(\%)$ & $(2: 1)^{2-}(\%)$ & $K_{1: 1}\left(\mathrm{M}^{-1}\right)$ \\
\hline 4 & 26.9 & 68.8 & 0.5 & 3.8 & - \\
\hline 5 & 24.5 & 70.9 & 0.3 & 4.3 & $24 \pm 1$ \\
\hline 6 & 14.4 & 68.7 & 1.7 & 15.2 & $93 \pm 1$ \\
\hline 7 & 16.1 & 66.3 & 2.9 & 14.7 & $630 \pm 20$ \\
\hline 8 & 14.3 & 68.9 & 1.3 & 15.5 & $1790 \pm 80$ \\
\hline 10 & 12.1 & 70.7 & 2.1 & 15.1 & - \\
\hline 12 & 14.8 & 69.4 & 1.4 & 14.4 & - \\
\hline
\end{tabular}

aThe equilibrium association constants for the $K_{1: 1}[23]$ are included.

molecules resulted in false negatives. The authors concluded that the complexes observed were electrostatic adducts formed in the electrospray process rather than specific inclusion complexes. However, gas-phase studies on electrospray-produced complexes of $\beta-C D$ and amino acids have shown that these complexes adopted an inclusion structure [19-21]. Molecular modeling calculations suggest that nonspecific complexes in the solution may convert to inclusion complexes in the gas phase. The evidence for gas-phase inclusion complexes does not necessarily confirm the presence of solutionphase inclusion complexes [21].

Here we report the ES-MS study of $\alpha$-cyclodextrin complexes with $\alpha, \omega$-dicarboxylic acids of different chain lengths. In solution, the equilibrium binding constant of $\alpha-\mathrm{CD}$ with aliphatic molecules increases with the chain length. This is attributed to the hydrophobic effect $[22,23]$. Our aim is to further investigate the origin of the cyclodextrin complexes that are observed in ES-MS. Do they form only owing to random electrostatic aggregation during the electrospray process, or do the hydrophobic interactions present in solution still play a role?

\section{Experimental}

All chemicals were purchased from Aldrich and used without purification. Stock solutions of $\alpha$-cyclodextrin $(\alpha-\mathrm{CD})$ and maltohexaose $(\mathrm{MH})$ were prepared in doubly distilled water at a concentration of $5.0 \times 10^{-3} \mathrm{M}$. All stock solutions of $\alpha, \omega$-dicarboxylic acids ${ }^{-}$OOC$\left(\mathrm{CH}_{2}\right)_{n}-\mathrm{COO}^{-}\left(5.0 \times 10^{-3} \mathrm{M}\right)$ were prepared in aqueous $\mathrm{NH}_{4} \mathrm{OH}(\mathrm{pH}=9)$. All along the text, the diacids will be noted " $1, n-\mathrm{da}^{\prime}$ with $n$ indicating the chain length. The solutions of complexes were prepared by mixing equimolar amounts of $\alpha$-CD or $\mathrm{MH}$ and $\alpha, \omega$-diacids. The stock solutions were diluted to their final concentration with aqueous $\mathrm{NH}_{4} \mathrm{OH}(\mathrm{pH}=9)$.

ES-MS analyses were performed on a Q-TOF2 mass spectrometer (Micromass, Manchester, UK) equipped with a Z-spray source. Aqueous sodium iodide was used for mass calibration. For electrospray experiments, the samples were injected at a flow rate of $5 \mu \mathrm{l} / \mathrm{min}$. Electrospray ionization was achieved by application of $-2.5 \mathrm{kV}$ on the needle. The source block temperature was set to $80{ }^{\circ} \mathrm{C}$, and the desolvation gas to $100{ }^{\circ} \mathrm{C}$.
Unless mentioned otherwise, the cone voltage was set to $10 \mathrm{~V}$. For each mass spectrum, 150 scans were summed, in order to have a high signal-to-noise ratio ( $\geq 200$ for the peak of the $(1: 1)^{2-}$ complex) and good statistics for the relative intensities. For replicate measurements the same day with the same injected solution, the standard deviation on the relative intensities is at maximum $0.3 \%$, and for replicate measurements on different days (over 1 month) with different solutions, the standard deviation is at maximum $2 \%$. For tandem mass spectrometry (MS/MS), argon was used as the collision gas. The collision-induced dissociation experiments were performed in the hexapole collision cell by applying a collision energy from 4 to $40 \mathrm{eV}$. 150 scans were summed for each spectrum.

\section{Results and Discussion}

\section{Stoichiometry of the Complexes}

The complexation of aliphatic diacids with $\alpha$-CD was investigated in the negative ion mode for a concentration range from $4.0 \times 10^{-4} \mathrm{M}$ to $2.0 \times 10^{-3} \mathrm{M}$. The choice of the concentration range was directed by the solution binding constants $K_{1: 1}$, which are from the millimolar to the molar range (see Table 1 ). Figure 1 shows MS spectra of equimolar mixtures $\left(4.0 \times 10^{-4} \mathrm{M}\right)$ of (Figure 1a) $\alpha-\mathrm{CD}$ and 1,5-da, and (Figure 1b) $\alpha-\mathrm{CD}$ and 1,10-da. The relative intensity of the singly charged

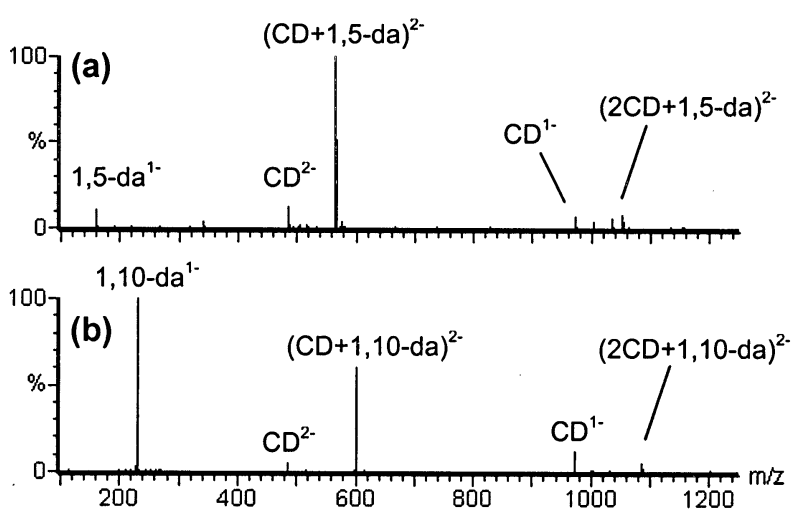

Figure 1. Full scan electrospray mass spectra obtained for equimolar mixtures $\left(4 \times 10^{-4} \mathrm{M}\right)$ of $(\mathbf{a}) \alpha$-CD and 1,5-diacid and (b) $\alpha$-CD and 1,10-diacid in water $(\mathrm{pH}=9)$. 
free diacid depends dramatically on the chain length: The longer the chain, the larger the surface activity and the greater the electrospray response. The diacid could only be detected as a singly charged species. We can also see in the spectra signals corresponding to the free $\alpha$-CD (singly and doubly deprotonated). However, the complexes with diacids are predominantly doubly charged. One can see a major peak corresponding to the 1:1 complex, and a minor peak corresponding to a $2: 1$ complex (two cyclodextrins + one diacid). These observations hold for the whole concentration range.

The stoichiometry of cyclodextrin complexes with $\alpha, \omega$-alkanedicarboxylate anions in solution has been discussed by different groups. Castronuovo et al. [23] have successfully fitted calorimetric titration curves $(\mathrm{pH}=11.3)$ by a $1: 1$ model $\left(\mathrm{n}_{\mathrm{CH} 2}=5-9\right)$. Similarly, Gómez-Orellana et al. [22] obtained results consistent with a 1:1 complex in the millimolar concentration range $\left(n_{\mathrm{CH} 2}=6-8\right)$. However, Eliadou et al. [24] detected by NMR the simultaneous presence of $1: 1$ and 2:1 complexes of $\alpha$-CD with 1,11-diacid at $\mathrm{pH}=13.6$. The chemical shifts in the NMR spectra were attributed to a pseudorotaxane inclusion (threading of the guest molecule into the $\alpha$-CD), but the binding constants could not be determined. Wilson et al. [25] performed a volumetric study on $\alpha$-CD $+\alpha$, $\omega$-alkanedicarboxylate anions at $\mathrm{pH}=10.5$ and concluded that 2:1 complexes are formed when $\mathrm{n}_{\mathrm{CH} 2} \geq 10$ by threading of the alkyl chain in the interior of the cyclodextrin. The calculated binding constants $K_{1: 1}$ are around $10^{3} \mathrm{~kg} \mathrm{~mol}^{-1}$, and $K_{2: 1}$ around $10^{2} \mathrm{~kg}^{2} \mathrm{~mol}^{-2}$. Our spectra show a signal corresponding to a 2:1 complex for all diacids studied (with higher relative intensity for $n_{\mathrm{CH} 2} \geq 6$, see Table 1 ). The specificity of these complexes is discussed below.

\section{Charge States of Free and Complexed Diacids}

At the $\mathrm{pH}$ used in this study, the diacids are completely doubly deprotonated in solution. However, as already pointed out in other studies in methanol/water or acetonitile/water solvents [26, 27], the full scan MS spectra of pure diacids show signals from both the singly- and the doubly-charged species. For aliphatic diacids, the fact that the molecule is doubly-charged in solution is not sufficient to ensure that only the doublycharged species is observed in the mass spectra. The charge state distribution depends on the size of the molecule rather than on its charge in solution. We repeated these measurements in pure water and observed the same behavior (data not shown). The relative intensity $\mathrm{RI}=\mathrm{I}\left(\mathrm{da}^{2-}\right) /\left[\mathrm{I}\left(\mathrm{da}^{2-}\right)+\mathrm{I}\left(\mathrm{da}^{1-}\right)\right]$ of the doubly charged species increases with the diacid chain length. In order to observe the doubly-charged diacid, the MS profile of the quadrupole has to be set to have a good transmission at low masses. In the MS spectra shown in Figure 1, the MS profile, set with the maximum transmission at $m / z=250$, is responsible for the fact that we cannot observe any doubly-charged diacid. For free diacids, the shorter the chain, the lower the relative intensity of doubly-charged species. For complexed diacids, however, there is a very small influence of the chain length on the charge state. The complexes are almost only ( $>95 \%$ ) doubly-deprotonated; chain length no longer has any influence on the observed charge state.

\section{Influence of Chain Length on the Relative Abundance of Complex}

The relative intensities of the $\alpha-\mathrm{CD}$, the 1:1 complex and the $2: 1$ complex observed in the mass spectra are given in Table 1 for the equimolar mixtures of $\alpha-\mathrm{CD}$ and diacids of different chain lengths. The intensities of the diacids were not taken into account for calculation of the percentages. As the response of the diacid depends dramatically on the chain length, including the diacid intensities would have biased our interpretation. The intensity of the complex is therefore better reported relative to the intensity of free $\alpha$-CD.

In solution, it is well known that the equilibrium association constant $K_{1: 1}$ of the $(\alpha-C D+$ diacid $)$ complex depends on the chain length of included diacid: the longer the chain, the larger the association constant [22, 23, 25]. The constants reported in reference [23] are included in Table 1 . Similar results have also been obtained for other $\alpha, \omega$-alkanedifunctional guests [28, 29], and the increase of the association constant with the chain length is attributed to an incremental contribution of the methylene groups included in the cavity. Volumetric studies are also consistent with inclusion of the guest into the cyclodextrin cavity [25]. In the full scan mass spectra, the relative abundance of the signals from the 1:1 complex does not depend significantly on the chain length of the dicarboxylic acids. There is clearly a discrepancy between the amount of complex known to be present in solution and the amount of complex effectively detected by ES-MS.

The present results interestingly parallel those obtained by Robinson et al. [30] on ACBP protein-CoA ligand complexes. In solution, the large increase of the association constant with the increase of the length of the hydrophobic acyl chain of the ligand has been attributed to the hydrophobic effect. In the ES-MS spectra, however, these large differences were not reflected by the proportions of complexed to uncomplexed species: a similar ratio of the complexed to free protein was observed irrespective of the ligand [30].

Does this mean that the observed complexes result from nonspecific associations? In order to get more information on the nature of the complexes formed with $\alpha$-cyclodextrin, we acquired full scan ES-MS spectra of all diacids with another ligand, maltohexaose.

\section{Comparison with Maltohexaose}

Maltohexaose is the linear analog of $\alpha$-CD. There are very few reports on maltohexaose complexation ability 


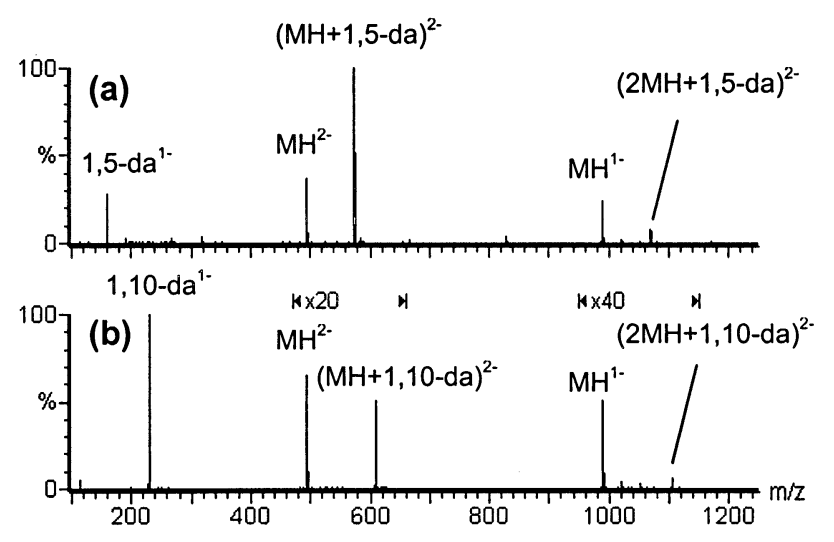

Figure 2. Full scan electrospray mass spectra obtained for equimolar mixtures $\left(4 \times 10^{-4} \mathrm{M}\right)$ of (a) maltohexaose and 1,5diacid and (b) maltohexaose and 1,10-diacid in water $(\mathrm{pH}=9)$. Note the different magnification factors in spectrum (b).

in solution, and in all cases the equilibrium association constants were found to be about $2-3$ orders of magnitude lower than for the corresponding inclusion complexes with cyclodextrins [31,32]. Maltohexaose cannot form inclusion complexes in solution, and hydrogen bonds between the $\mathrm{OH}$ groups of the sugar and the guest are thought to be responsible for the weak binding (hydrogen bonding interactions are disfavored in water) [33].

Comparison with maltohexaose has already been used as a test for the specific detection of inclusion complexes with $\alpha$-CD by FAB [34] or ionspray [35, 36] mass spectrometry. We use the same approach here to investigate the possible contribution of nonspecific complexes to the signal of the cyclodextrin complexes in our experimental conditions. It is assumed that maltohexaose forms no specific inclusion complex with aliphatic diacids in solution in the millimolar concentration range. There should therefore be no signal corresponding to the complex in the mass spectra. However, the full scan ES-MS spectra of mixtures of maltohexaose and dicarboxylic acids show signals corresponding to both $(1: 1)^{2-}$ and $(2: 1)^{2-}$ complexes (Figure 2). The relative intensities observed for the equimolar mixtures of maltohexaose and the different diacids are given in Table 2. Contrary to the case of $\alpha-C D$, dependency of the relative intensities of the complexes on chain length of the diacids is significant: the shorter the chain length, the larger the relative intensity of the complex with maltohexaose. These results suggest that
Table 2. Relative intensities of maltohexaose and the complexes with diacids of different chain length for equimolar mixtures $\left([\mathrm{MH}]=[1, \mathrm{n}\right.$-da $\left.]=4 \times 10^{-4} \mathrm{M}\right)$

\begin{tabular}{ccccc}
\hline $\mathrm{n}\left(\mathrm{CH}_{2}\right)$ & $\mathrm{MH}(\%)$ & $(1: 1)^{2-}(\%)$ & $(1: 1)^{1-}(\%)$ & $(2: 1)^{2-}(\%)$ \\
\hline \hline 4 & 7.8 & 87.6 & - & 4.6 \\
5 & 7.0 & 89.0 & - & 4.0 \\
6 & 16.0 & 81.4 & - & 2.6 \\
7 & 17.6 & 79.1 & - & 3.3 \\
8 & 20.6 & 76.2 & - & 3.2 \\
10 & 43.9 & 53.9 & 0.5 & 1.7 \\
12 & 47.5 & 50.5 & 0.4 & 1.6 \\
\hline
\end{tabular}

in the case of the cyclodextrin, at least part of the observed complex species may result from nonspecific (non-inclusion) complex formation. Moreover, the shorter the diacid, the greater the tendency to form this kind of adduct.

\section{Dilution Tests}

Ideally, electrospray should provide a faithful image of the composition of the solution. But electrospray is not an instantaneous process: changes can occur during the evolution from the initial charged droplet to the final emission of the ion in the gas phase. In particular, evaporation of the droplet can cause a displacement of the complexation equilibrium towards association if the association kinetics is fast enough compared to evaporation. Moreover, nonspecific aggregation can occur at the droplet/vacuum interface that can be different from specific aggregation in the bulk solvent. Such processes are extremely important because the ions are expelled from the surface of the charged droplet upon uneven Rayleigh fissions [37, 38].

It has been suggested that lowering the sample concentration and the electrospray flow rate helps to prevent such nonspecific aggregation $[1,4]$. We therefore lowered the concentration close to the electrospray detection limit $\left(4 \times 10^{-5} \mathrm{M}\right)$ for 1,10-da complexes with $\alpha$-CD and maltohexaose complexes. The relative intensities are summarized in Table 3. For shorter diacids like 1,5-da, the signal-to-noise ratio was too low in the entire mass spectrum. For the complex with $\alpha$-CD, lowering the concentration moderately reduces the proportion of 1:1 complex, but the signal of the 2:1 complex almost vanishes. In the case of $\mathrm{MH}$, the intensity of all complexes is dramatically reduced upon dilution. These results suggest that the $1: 1$ complex with $\alpha$-CD is

Table 3. Relative intensities measured in the spectra of equimolar mixtures of $\alpha$-cyclodextrin and maltohexaose with 1,10-diacid obtained by electrospray for different concentrations

\begin{tabular}{cccccc}
\hline & Concentration & Ligand $^{\text {a }}(\%)$ & $(1: 1)^{2-}(\%)$ & $(1: 1)^{1-}(\%)$ & $(2: 1)^{2-}(\%)$ \\
\hline \hline$\alpha$-CD & $4 \times 10^{-4} \mathrm{M}$ & 12.1 & 70.7 & 2.1 & 15.1 \\
& $4 \times 10^{-5} \mathrm{M}$ & 44.6 & 54.7 & 0.3 & 0.4 \\
$\mathrm{MH}$ & $4 \times 10^{-4} \mathrm{M}$ & 43.9 & 53.9 & 0.5 & 1.7 \\
& $4 \times 10^{-5} \mathrm{M}$ & 89.1 & 6.1 & 4.8 & - \\
\hline
\end{tabular}

aLigand stands for either $\alpha$-CD or $\mathrm{MH}$ (singly + doubly charged). 


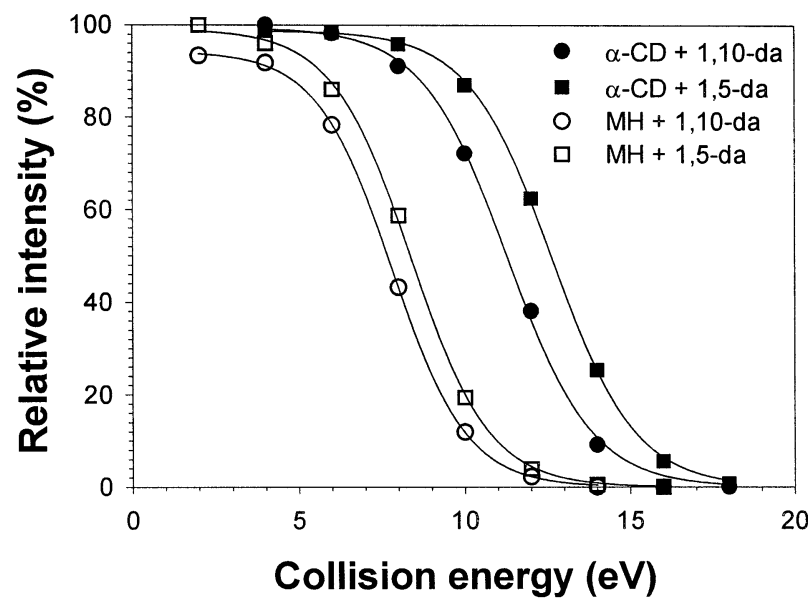

Figure 3. Relative intensity of complex as a function of the collision energy obtained in the MS/MS experiments on the $(1: 1)^{2-}$ complexes between $\alpha$-cyclodextrin $(\alpha$-CD) or maltohexaose $(\mathrm{MH})$ and 1,5- or 1,10-diacids. The relative intensities are calculated using eq 1.

specific, but that the 2:1 complex with $\alpha$-CD and both complexes with $\mathrm{MH}$ are nonspecific.

\section{MS/MS Experiments}

Tandem mass spectrometry experiments were performed on the doubly-charged 1:1 complexes between the diacids and $\alpha$-cyclodextrin or maltohexaose. We used a cone voltage of $10 \mathrm{~V}$, and monitored the fragmentation upon increasing the collision energy. The fragments were singly charged dextrin and diacid. The following equation was used to calculate the relative intensity (RI) of a surviving parent ion at each collision energy.

$$
\mathrm{RI}(\%)=\frac{I_{(1: 1)^{2-}}}{I_{(1: 1)^{2-}}+\frac{I_{(d a)^{1-}}+I_{(\text {ligand })^{1-}}}{2}} \cdot 100 \%
$$

Where da stands for the diacid and ligand stands for either $\alpha$-CD or MH. In the case of the complex with maltohexaose, at values of collision energy $>10 \mathrm{eV}$, there are signals from maltohexaose fragments. In order to be able to compare those results with MS/MS measurement with $\alpha-\mathrm{CD}$, we added the intensity of the fragments to the intensity of the free ligand.

The fragmentation curves (Figure 3) show that higher collision energies are required to fragment complexes with $\alpha$-CD than corresponding complexes with maltohexaose. This indicates that the interactions are stronger with $\alpha-\mathrm{CD}$ than with $\mathrm{MH}$. The hydrophobic effect, which is purely an entropic effect caused by the reorganization of water upon complexation, cannot be invoked in the gas phase. However, van der Waals contacts between the host and the guest can remain in the gas phase and contribute to the overall stability.

The dependence of the gas-phase kinetic stability on chain length is more intriguing. For both $\alpha-C D$ and maltohexaose complexes, a larger collision energy is needed for the dissociation of complexes with shorter diacids. This is exactly the reverse trend compared to the solution phase, where for $\alpha-\mathrm{CD}$, more stable complexes are formed with longer chains. No satisfactory explanation could be found to account for the higher gas-phase kinetic stability of complexes with shorter chains. The effect of the number of degrees of freedom on the dissociation kinetics would have given the opposite trend [39]. The Coulombic repulsion between the charged fragments cannot be invoked either, as a stronger repulsion is expected for the shorter diacids, due to the proximity of the charges. Nevertheless, independently of mechanistic considerations, these MS/MS results further confirm that nonspecific aggregation must occur at the droplet surface during the electrospray process. The higher gas-phase stability of the complexes with shorter diacids is consistent with the higher relative intensity of nonspecific complex observed with maltohexaose for shorter diacids (see Table 2). The nonspecific complexes are therefore due to electrostatic interactions (hydrophobic or van der Waals interactions would have given the opposite trend).

\section{Specificity of the Cyclodextrin Complexes}

The 1:1 complexes with $\alpha$-CD have some characteristics of specific complexes (they are more resistant to dilution and to collision-induced dissociation than the complexes with maltohexaose), and also show some characteristics of nonspecific complexes (relative intensities of the complexes are not correlated with their abundance in solution). The observation of complexes with maltohexaose implies that, in similar conditions, nonspecific adducts can also form with $\alpha$-CD. This suggests that the total intensity of the 1:1 complex results from two contributions: One from specific complexes and one from nonspecific adducts.

The spectra obtained with the linear analog maltohexaose can be used to evaluate the proportion of nonspecific adduct in the spectra of $\alpha$-CD complexes, assuming that the complex with $\mathrm{MH}$ is entirely nonspecific (see discussion above) and that the amount of nonspecific complex formed with $\alpha$-CD is the same as the amount formed with $\mathrm{MH}$ when the experimental conditions are identical. We also assume that the response of the nonspecific complex with $\mathrm{MH}$ is the same as the response to the nonspecific complex with $\alpha$-CD. In Tables 1 and 2, the percentages of relative intensity have been calculated by defining I(MH or $\alpha-\mathrm{CD})+$ $\mathrm{I}($ complexes $)=100 \%$. To be able to compare the relative intensities of the complexes in Tables 1 and 2, we have determined the ratio between the electrospray responses of $\alpha-\mathrm{CD}$ and $\mathrm{MH}$ by measuring the intensity ratio in the MS spectrum of an equimolar mixture of those two compounds. The response to $\mathrm{MH}$ is 3.7 times lower than the response to $\alpha-\mathrm{CD}$. This means that the relative intensities of the complexes in Table 2 are 

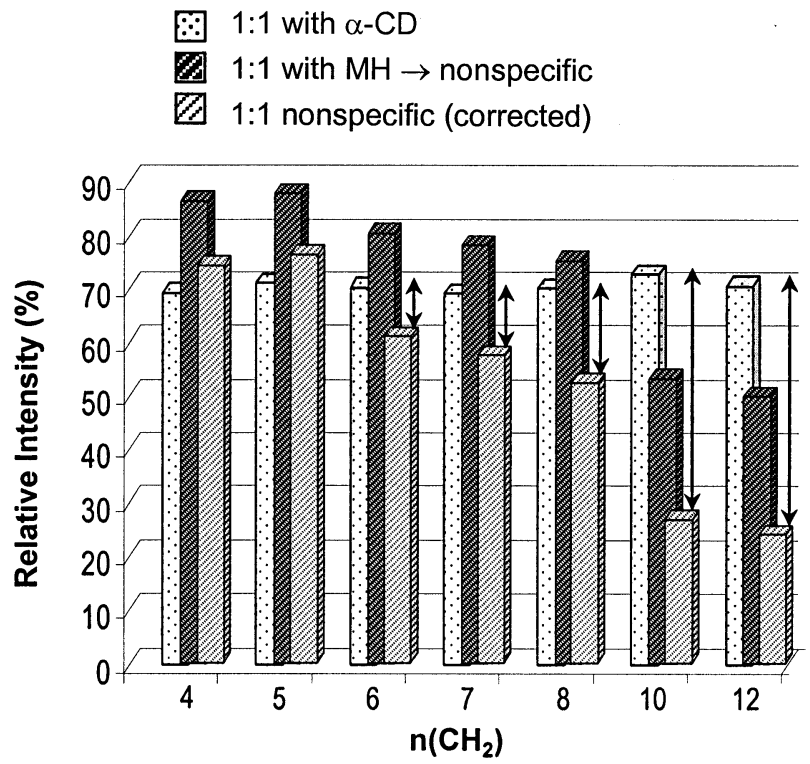

Figure 4. Relative intensities of the 1:1 complex with $\alpha$-CD (white bar with dots), the 1:1 complex with MH (gray bar with dark hatches), the 1:1 complex with $\mathrm{MH}$ after correction as explained in the text (gray bar with light hatches). Arrows represent the difference between the total intensity of the complex with $\alpha$-CD and the nonspecific contribution calculated from the spectra obtained with maltohexaose (see text for details), and their heights are proportional to the signal due to the contribution of specific (inclusion) complex.

overestimated compared to those in Table 1 because of the lower relative response of $\mathrm{MH}$. To correct for the relative response of $\mathrm{MH}$ and $\alpha-\mathrm{CD}$, we multiplied the relative intensity of $\mathrm{MH}$ in Table 2 by 3.7, and then rescaled all relative intensities to $100 \%$. The results are reported in Figure 4. For each diacid, the white bar with dots represents the relative intensity of the 1:1 complex with $\alpha-C D$, the gray bar with dark hatches represents the relative intensity of the 1:1 complex with $\mathrm{MH}$, and the gray bar with light hatches represents the relative intensity of the 1:1 complex with $\mathrm{MH}$ after correction, as explained above. The latter therefore represents the relative intensity of nonspecific complex formed with $\alpha$-CD. This contribution decreases as the chain length increases due to the electrostatic interactions (see the MS/MS section).

The difference in height (represented by the arrows) between the total intensity of 1:1 complex with $\alpha$-CD (first bar) and the nonspecific contribution (third bar) represents the signal due to the contribution of specific (inclusion) complex. We can see that for $\mathrm{n}_{\mathrm{CH} 2}=4$ and $\mathrm{n}_{\mathrm{CH} 2}=5$, the correction factor that scales the nonspecific contribution gives approximately equal relative intensities for the complex with $\alpha-\mathrm{CD}$ and the nonspecific complex. As the chain length increases from $\mathrm{n}_{\mathrm{CH} 2}=6$ to 10 , the signal due to specific inclusion complex increases, and then levels off. This behavior is in nice agreement with the solution behavior [23] (see constants in Table 1).

\section{Conclusions}

The electrospray process consists of pulling ions out of the solution. If the transfer of the analytes from the bulk solution to the vacuum were instantaneous, the mass spectrum would be like a snapshot of the solution, and would give a faithful image of its composition, provided that all species are kinetically stable enough to reach the detector intact. Unfortunately, this is not the case, and nonspecific adducts can form during the solution-to-vacuum transfer, due to electrostatic interactions at the surface of the evaporating charged droplets. Nonspecific aggregation occurs mostly in the case of hydrophobic complexes [30,40], because the removal of the solvent causes a complete reversal of the relative scale of the interactions in the complex. The hydrophobic effect comes from the solvent reorganization upon complexation. Electrostatic interactions, however, are shielded by the dielectric constant of the solvent and do not always result in a favorable Gibbs free energy for the formation of the complex, due to enthalpy/entropy compensation effects [41]. In vacuum, the hydrophobic driving force disappears (only van der Waals interaction can persist at the contact region between the host and the guest), while electrostatic interactions, among which are hydrogen bonds, are reinforced in vacuum compared to the solution.

The experiments described in the present article allowed distinction of two contributions to the cyclodextrin complexes detected by electrospray mass spectrometry. We are undoubtedly faced with a contribution of nonspecific aggregation, but the comparative experiments with the linear analog maltohexaose show that nonspecific aggregation cannot account for the total intensity of the complex. There is therefore another contribution attributed to the inclusion complexes that are present in the bulk solution. This could mean that the kinetics of the electrospray process can still allow some inclusion complexes present in solution to be transferred to the gas phase, in addition to the nonspecific complexes formed by aggregation. Once transferred to the gas phase, these inclusion complexes may further change conformation. The MS/MS experiments showed that complexes with cyclodextrins seem to have an "extra"stabilization compared to complexes with maltohexaose, which could be due to van der Waals contacts in the interior of the cavity.

The problem of nonspecific aggregation due to electrostatic interactions is believed to be widely encountered when investigating hydrophobic complexes by mass spectrometry. Cyclodextrin complexes are an excellent model of hydrophobic complexes. What can therefore be predicted for the study of biological complexes in general? In molecular biology, there is a long and lively debate about how important relative interactions are for the formation of complexes [42-45]. Hydrophobic interactions usually contribute greatly to the stability of the complexes: there is often a nice correlation between the binding constant and the contact 
surface area between the partners of the complex. It may therefore appear relatively tricky to study these complexes by electrospray. Nevertheless, it must be kept in mind that hydrophobic interactions are not local, but constitute a global entropic effect that favors the bringing together of nonpolar surfaces. However, the specificity of a complex, which is essential for its function, is induced by directional interactions (ion-ion, ion-dipole, hydrogen bonds. . .) between complementary donor-acceptor sites at the interface. As explained above, these interactions are maintained, and even reinforced when the solvent is removed. We can therefore reasonably expect that electrospray mass spectrometry will be convenient for the specific detection of most biological complexes, with the exception of the complexes that are stabilized almost exclusively by hydrophobic interactions [30,40].

\section{Acknowledgments}

NG is grateful to the S.S.T.C. (Services Fédéraux des Affaires Scientifiques, Techniques et Culturelles) for a postdoctoral research grant. VG is indebted to the F.N.R.S (Fonds National de la Recherche Scientifique) for a research fellowship. This work has been supported by the A.R.C (Actions de Recherche Concertées/ Communauté Française de Belgique).

\section{References}

1. Smith, R. D.; Light-Wahl, K. J. The Observation of NonCovalent Interactions in Solution by Electrospray Ionization Mass Spectrometry: Promise, Pitfalls, and Prognosis. Biol. Mass Spectrom. 1993, 22, 493-501.

2. Smith, D. L.; Zhang, Z. Probing Non-Covalent Structural Features of Proteins by Mass Spectrometry. Mass Spectrom. Rev 1994, 13, 411-429.

3. Vincenti, M. Host-Guest Chemistry in the Mass Spectrometer. J. Mass Spectrom. 1995, 30, 925-939.

4. Smith, R. D.; Bruce, J. E.; Wu, Q.; Lei, Q. P. New Mass Spectrometric Methods for the Study of Non-Covalent Associations of Biopolymers. Chem. Soc. Rev. 1997, 26, 191-202.

5. Loo, J. A. Studying Non-Covalent Protein Complexes by Electrospray Ionization Mass Spectrometry. Mass Spectrom. Rev. 1997, 16, 1-23.

6. Schalley, C. A. Supramolecular Chemistry Goes Gas Phase: the Mass Spectrometric Examination of Non-Covalent Interactions in Host-Guest Chemistry and Molecular Recognition. Int. J. Mass Spectrom. 2000, 194, 11-39.

7. Rekharsky, M. V.; Inoue, Y. Complexation Thermodynamics of Cyclodextrins. Chem. Rev. 1998, 98, 1875-1917.

8. Szejtli, J. Introduction and General Overview of Cyclodextrin Chemistry. Chem. Rev. 1998, 98, 1743-1753.

9. Connors, K. A. The Stability of Cyclodextrin Complexes in Solution. Chem. Rev. 1997, 97, 1325-1357.

10. Saenger, W. Cyclodextrin Inclusion Compounds in Research and Industry. Angew. Chem. Int. Ed. 1980, 19, 344-362.

11. Selva, A.; Redenti, E.; Zanol, M.; Ventura, P.; Casetta, B. A Study of $\beta$-Cyclodextrin and Its Inclusion Complexes with Piroxicam and Tefenadrine by Ionspray Mass Spectrometry. Org. Mass Spectrom. 1993, 28, 983-986.

12. Camilleri, P.; Haskins, N. J.; New, A. P.; Saunders, M. R. Analyzing of the Complexation of Amino Acids and Peptides with $\beta$-Cyclodextrin Using Electrospray Ionization Mass Spectrometry. Rapid Commun. Mass Spectrom. 1993, 7, 949-952.
13. Haskins, N. J.; Saunders, M. R.; Camilleri, P. The Complexation and Chiral Selectivity of 2-Hydroxypropyl- $\beta$-Cyclodextrin with Guest Molecules as Studied by Electrospray Mass Spectrometry. Rapid Commun. Mass Spectrom. 1994, 8, 423-426.

14. Ramanathan, R.; Prokai, L. Electrospray Ionization Mass Spectrometric Study of Encapsulation of Amino Acids by Cyclodextrins. J. Am. Soc. Mass Spectrom. 1995, 6, 866-871.

15. Cescutti, P.; Garozzo, D.; Rizzo, R. Study of the Inclusion Complexes of Aromatic Molecules with Cyclodextrins Using Ionspray Mass Spectrometry. Carbohyd. Res. 1996, 290, 105115.

16. Cescutti, P.; Garozzo, D.; Rizzo, R. Effect of Methylation of $\beta$-Cyclodextrin on the Formation of Inclusion Complexes with Aromatic Compounds. An Ionspray Mass Spectrometry Investigation. Carbohyd. Res. 1997, 302, 1-6.

17. Lamcharfi, E.; Chuilon, S.; Kerbal, A.; Kunesch, G.; Libot, F.; Virelizier, H. Electrospray Ionization Mass Spectrometry in Supramolecular Chemistry: Characterization of Non-Covalent Cyclodextrin Complexes. J. Mass Spectrom. 1996, 31, 982-986.

18. Cunniff, J. B.; Vouros, P. False Positives and the Detection of Cyclodextrin Inclusion Complexes by Electrospray Mass Spectrometry. J. Am. Soc. Mass Spectrom. 1995, 6, 437-447.

19. Ramirez, J.; Ahn, S.; Grigorean, G.; Lebrilla, C. B. Evidence for the Formation of Gas-Phase Inclusion Complexes with Cyclodextrins and Amino Acids. J. Am. Chem. Soc. 2000, 122, 6884-6890.

20. Ahn, S.; Ramirez, J.; Grigorean, G.; Lebrilla, C. B. Chiral Recognition in Gas-Phase Cyclodextrin: Amino Acid Complexes-Is the Three Point Interaction Still Valid in the Gas Phase? J. Am. Soc. Mass Spectrom. 2001, 12, 278-287.

21. Lebrilla, C. B. The Gas-Phase Chemistry of Cyclodextrin Inclusion Complexes. Acc. Chem. Res. 2001, 34, 653-661.

22. Gomez-Orellana, I.; Hallen, D.; Stödeman, M. Microcalorimetric Titration of $\alpha$-Cyclodextrin with Some Straight-Chain $\alpha, \omega-$ Dicarboxylates in Aqueous Solution at Different Temperature. J. Chem. Soc. Faraday Trans. 1994, 90, 3397-3400.

23. Castronuovo, G.; Elia, V.; Velleca, F.; Viscardi, G. Thermodynamics of the Interaction of $\alpha$-Cyclodextrin with $\alpha, \omega$-Dicarboxylic Acids in Aqueous Solutions. A Calorimetric Study at $25^{\circ} \mathrm{C}$. Thermochimica Acta 1997, 292, 31-37.

24. Eliadou, K.; Yannakopoulou, K.; Rontoyianni, A.; Mavridis, I. M. NMR Detection of Simultaneous Formation of [2]- and [3]Pseudorotaxanes in Aqueous Solution Between $\alpha$-Cyclodextrin and Linear Aliphatic $\alpha, \omega$-Amino Acids, an $\alpha, \omega$-Diamine and an $\alpha, \omega$-Diacid of Similar Length, and Comparison with the Solid State Structures. J. Org. Chem. 1999, 64, 62176226.

25. Wilson, L. D.; Verrall, R. E. A Volumetric Study of Cyclodextrin- $\alpha-\omega$-Alkyl Dicarboxylate Anion Complexes in Aqueous Solutions. J. Phys. Chem. B 2000, 104, 1880-1886.

26. Siu, K. W. M.; Gardner, G. J.; Berman, S. S. Multiply Charged Ions in Ionspray Mass Spectrometry. Org. Mass Spectrom. 1989, 24, 931-942.

27. Aplin, R. T.; Moloney, M. G.; Newby, R.; Wright, E. NegativeIon Electrospray Mass Spectrometric Analysis of Dicarboxylic Acids. J. Mass Spectrom. 1999, 34, 60-61.

28. Bastos, M.; Briggner, L.-E.; Shehatta, I.; Wadsö, I. The Binding of Alkane- $\alpha, \omega$-Diols to $\alpha$,-Cyclodextrin. A Microcalorimetric Study. J. Chem. Thermodynamics 1990, 22, 1181-1190.

29. Castronuovo, G.; Elia, V.; Fessas, D.; Giordano, A.; Velleca, F. Thermodynamics of the Interaction of Cyclodextrins with Aromatic and $\alpha, \omega$-Amino Acids in Aqueous Solutions: a Calorimetric Study at $25^{\circ} \mathrm{C}$. Carbohydr. Res. 1995, 272, 31-39.

30. Robinson, C. V.; Chung, E. W.; Kragelund, B. B.; Knudsen, J.; Aplin, R. T.; Poulsen, F. M.; Dobson, C. M. Probing the Nature of Noncovalent Interactions by Mass Spectrometry. A Study of 
Protein-CoA Ligand Binding and Assembly. J. Am. Chem. Soc. 1996, 118, 8646-8653.

31. Komiyama, M.; Hirai, H.; Kobayashi, K. Complex-Forming Ability of Linear Glucose Oligomers As Non-Cyclic Analogs of Cyclodextrins. Makromol. Chem. Rapid Commun. 1986, 7, 739-742.

32. Aoyama, Y.; Otsuki, J.; Nagai, Y.; Kobayashi, K.; Toi, H. Host-Guest Complexation of Oligosaccharides-Interaction of Maltodextrins with Hydrophobic Fluorescence Probes in Water. Tetrahedron Lett. 1992, 33, 3775-3778.

33. Kano, K.; Minami, K.; Horigushi, K.; Ishimura, T.; Kodera, M. Ability of Non-Cyclic Oligosaccharides to Form Molecular Complexes and Its Use for Chiral Separation by Capillary Zone Electrophoresis. J. Chromatogr. A 2002, 694, 307-313.

34. Mele, A.; Selva, A. Detection of 1:1 Adducts of Piroxicam with $\beta$-Cyclodextrin or with Maltohexaose by Fast Atom Bombardment Mass Spectrometry. J. Mass Spectrom. 1995, 30, 645-647.

35. Selva, A.; Redenti, E.; Zanol, M.; Ventura, P.; Casetta, B. Letter: Support for the Proposedobservation by Ionspray Mass Spectrometry of Piroxicam $/ \beta$-Cyclodextrin and Tefenadrine $/ \beta$ Cyclodextrin Non-Covalent Inclusion Complexes. Eur. Mass Spectrom. 1995, 1, 105-106.

36. Bakhtiar, R.; Bulusu, S. Molecular Complexes of Cyclodextrins: Application of Ion-Spray Mass Spectrometry to the Study of Complexes with Selected Nitrosamines. Rapid Commun. Mass Spectrom. 1995, 9, 1391-1394.
37. Gomez, A.; Tang, K. Charge and Fission of Droplets in Electrostatic Sprays. Phys. Fluids 1994, 6, 404-414.

38. Kebarle, P. A Brief Overview of the Present Status of the Mechanisms Involved in Electrospray Mass Spectrometry. J. Mass Spectrom. 2000, 35, 804-817.

39. Gabelica, V.; De Pauw, E. Comparison Between SolutionPhase Stability and Gas-Phase Kinetic Stability of Oligodeoxynucleotide Duplexes. J. Mass Spectrom. 2001, 36, 397-402.

40. Li, Y.-T.; Hsieh, Y. L.; Henion, J. D.; Senko, M. W.; McLafferty, F. W.; Ganem, B. Mass Spectrometric Studies on Noncovalent Dimers of Leucine Zipper Peptides. J. Am. Chem. Soc. 1993, 115, 8409-8413.

41. Ross, P. D.; Rekharsky, M. V. Thermodynamics of Hydrogen Bond and Hydrophobic Interactions in Cyclodextrin Complexes. Biophys. J. 1996, 71, 2144-2154.

42. Pace, C. N. Evaluating Contribution of Hydrogen Bonding and Hydrophobic Binding to Protein Folding. Methods Enzymol. 1995, 259, 538-554.

43. Lo Conte, L.; Chothia, C.; Janin, J. The Atomic Structure of Protein-Protein Recognition Sites. J. Mol. Biol. 1999, 285, 2177-2198.

44. Kuntz, I. D.; Chen, K.; Sharp, K. A.; Kollman, P. The Maximal Affinity of Ligands. Proc. Natl. Acad. Sci. U.S.A. 1999, 96, 9997-10002.

45. Davis, A. M.; Teague, S. J. Hydrogen Bonding, Hydrophobic Interactions, and Failure of the Rigid Receptor Hypothesis. Angew. Chem. Int. Ed. Engl. 1999, 38, 736-749. 